\title{
FEDRA, DE JUAN MAYORGA: TEXTO Y REPRESENTACIÓN
}

\author{
JUAN MAYORGA'S PHAEDRA: TEXT, AND PERFORMANCE
}

Óscar BARRERO PÉREZ

Universidad Autónoma de Madrid oscar.barrero@uam.es

Resumen: Juan Mayorga estrenó en 2007 su versión de Fedra, partiendo básicamente del Hipólito de Eurípides. La desviación de esta nueva Fedra con respecto a la tradición del mito no resulta muy relevante, pero sí lo es el desenlace. La puesta en escena de la obra dio a entender un enamoramiento de Hipólito que no figura en el texto, lo que da pie a plantear, una vez más, las diferencias existentes entre un texto literario teatral y su representación. $\mathrm{O}$ las que puede haber entre la escritura teatral de un autor y la interpretación libre de quien la lleva a la representación.

Palabras clave: Juan Mayorga. Fedra. Texto teatral. Representación teatral

\begin{abstract}
Juan Mayorga premiered in 2007 his version of Phaedra, basically based on Hippolytus by Euripides. The deviation of this new Phaedra with respect to the tradition of the myth is not very relevant, but it is worthwhile in ending. The staging of the performance was given to understand a falling in love of Hippolytus that is not included in the text, which leads to raise, once again, the differences between a theatrical literary text and its performance. Or those who can be between the theatre writing of an author and the liberal interpretation of whom performs the play.
\end{abstract}

Keywords: Juan Mayorga. Phaedra. Theatrical text. Theatrical performance. 
a fuerza del mito de Fedra e Hipólito como tema literario es, todavía hoy, descomunal; hasta tal punto que está registrado más de un centenar de versiones teatrales y cinematográficas en el siglo XX y ya alcanza la docena el número de Fedras en lo que llevamos del XXI, de acuerdo con el recuento realizado recientemente por Andrés Pociña y Aurora López en un libro (2016: 11-27) que venía a completar otro suyo (2008) de idénticas características. Se trata, por tanto, de un mito extraordinariamente fecundo desde el punto de vista creativo: teatro, cine, novela, ensayo, o varias cosas a la vez, como sucede en el caso de Manuel García Viñó, narrador en Fedra (1975) y ensayista en El mito de Fedra (1983). Tal es su capacidad de atracción que, como ha señalado M. a José Ragué Arias (1986: 20), Fedra es, con Antígona, el personaje mitológico griego “de mayor protagonismo en el teatro del siglo XX en España."

La Fedra de quien acaso sea hoy el dramaturgo español más importante, Juan Mayorga, se estrenó en julio de 2007, en el Teatro Romano de Mérida. La fuente en la que se inspira el texto editado que utilizaré para la comparación (Mayorga, 2010) es, básicamente, la obra de Eurípides que se representó en la Atenas del año 428 a. C. y que los especialistas conocen con el título de Hipólito coronado o Hipólito II, cuyo ordinal responde al hecho de que hubo otra pieza anterior, un Hipólito I o Hipólito velado. Del Hipólito II —o, simplemente, Hipólito - han bebido, con mayor o menor aprovechamiento, las Fedras posteriores, ya que del I y del intermedio entre este y el II, el escrito por Sófocles, no conocemos más que fragmentos.

La fuente de la que se nutre en mayor medida Mayorga es Eurípides, a quien adapta y actualiza a partir de una base ya utilizada por Miguel de Unamuno (1988): la humanización de los personajes en un tiempo ya carente de dioses y que, por tanto, impide que lo que suceda sobre la escena dependa de la intervención de ninguna deidad, a no ser que la nueva versión se plantee como una reconstrucción arqueológica. Entre los tres procedimientos que Christina Mougoyanni Hennessy (2006: 90) señala como posibilidades de reinterpretación de los mitos griegos por el teatro español contemporáneo, la remitificación o "inversión del mensaje ideológico, pero respetando el contenido mítico", la "desmitificación o humanización" y la "esperpentización mitológica", Mayorga elige, como hizo Unamuno, la segunda.

En el mito era una despechada Afrodita la responsable de la pasión de Fedra hacia su hijastro, a quien la diosa decidía castigar por su indiferencia en materia amorosa. Así, con la explicación de Afrodita en el prólogo, se iniciaba la obra de Eurípides. La versión de Mayorga prescinde de la intervención de cualesquiera elementos que distraigan de la fuerza catalizadora de la trama: la pasión erótica. Su Fedra se sitúa al margen de cualquier tiempo preciso, y así, por ejemplo, se mencionan (Mayorga, 2010: 79) los planetas, que no llegarían a reconocerse históricamente hasta 1610. Este detalle no significa que la acción deba situarse después de esta fecha. Pero tampoco antes, porque no hay tiempo ni espacio en esta Fedra en la que no existen dioses, pero sí amazonas, y en la que, como 
en el relato mítico, uno de los personajes es un rey que se comporta como un monarca de la antigüedad. Sería inútil buscar una no pretendida coherencia cronológica: no la habría ni en los usos lingüísticos.

La Fedra de Mayorga pone el acento en la pasión humana a la que está entregada la protagonista: el argumento queda circunscrito al deseo físico. Es ese deseo carnal lo que da sentido a la reiterada presencia de la palabra cuerpo, que aparece nada menos que veinticuatro veces en el texto. La intensidad de este erotismo difícilmente identificable con el amor propiamente dicho se palpa desde la aparición de Fedra hasta su suicidio. Por dos veces, al empezar las escenas 6 y 8, la encontramos contemplando su imagen ante el espejo y recreándose en su cabello, elemento erótico en casi cualquier cultura: "Se mira en el espejo, se suelta el pelo, se lo recoge, cambia una y otra vez de peinado, siempre insatisfecha" (Mayorga, 2010: 65); "Ante el espejo, Fedra encuentra su peinado, se gusta, canturrea" (Mayorga, 2010: 74).

No es únicamente un pecado de lujuria, y quizá también incesto para nuestra concepción actual — téngase en cuenta que la obra carece de ambientación espacial o cronológica-, el que comete la Fedra de Mayorga. También puede acusársela de orgullo, por el afán de imponer su dominio sobre aquel a quien aún ninguna mujer ha conseguido seducir. Ella sería la primera que se vanagloriaría de lograrlo: "Sé que yo podría ganar lo que ninguna otra ha alcanzado" (Mayorga, 2010: 51). La presa le resulta más apetecible en tanto en cuanto todos los atenienses saben que el objetivo en que ha puesto sus ojos es reacio al contacto con el otro sexo.

¿Por qué su resistencia? Mayorga, como otros autores que antes de él recrearon el mito, no explica con claridad los motivos concretos, pero se vislumbra la importancia del papel jugado por el rechazo que la madrastra sentía hacia el niño:

Desde el principio te propusiste hacerme daño. Era un niño y no entendía por qué me mostrabas tu enemistad. Solo hablabas de mí a mi padre para herirme. Apenas era un muchacho cuando hiciste que me enviase lejos. Aquellos años ¡cómo eché de menos sus brazos, fuertes y tiernos, y cómo te odié por haberme separado de él! ¡Cuánto te odié, Fedra! (Mayorga, 2010: 76).

Las versiones del mito no son coincidentes sobre la historia de la amazona Antíope, quien habría de ser esposa de su raptor, el rey de Atenas, Teseo, una y otro padres de Hipólito. En la de Mayorga, Antíope quedó relegada por Teseo en favor de Fedra, convertida así en madrastra de Hipólito. De manera que fue la pasión erótica suscitada por Fedra la que hizo que Teseo abandonara a Antíope. El repudio mostrado por Hipólito hacia las mujeres derivaría, así, del que siente hacia aquella mujer causante del distanciamiento de sus padres y, al mismo tiempo, de su orfandad:

Es verdad que os prefiero lejos. No hay peor calamidad que la mujer. La mujer asedia el espíritu del hombre y lo llena de deseos insensatos de los que resultan las peores desgracias. He visto a grandes hombres destruidos por la mujer. Por vuestra culpa ha corrido mucha sangre. [...] Quizá sea esa la causa de mi enemistad hacia vosotras. [...] He visto a mi padre lleno de ciega alegría o de ciega pesadumbre por culpa de eso que llaman amor, la más detestable de las pasiones. Yo no caeré en esa trampa. Lo juro (Mayorga, 2010: 68-69).

En la versión de Séneca se apunta discretamente otro motivo del rechazo de Hipólito al contacto con el sexo femenino: la herencia genética: "Con aborrecimiento huye de cualquier tipo de mujer. 
Implacable, consagra sus años a una vida célibe, evita las relaciones amorosas: puedes ver que tiene raza de amazonas" (Séneca, 1980: 37). Más elípticamente, se alude a eso mismo en la Fedra de Mayorga: "Una amazona te llevó en su seno, naciste en el bosque y tienes su dureza, nadie te ha enseñado a amar" (Mayorga, 2010: 81).

En la Fedra de Mayorga queda un rastro del determinismo de su predecesora griega. Si a la original no cabe reprocharle nada, porque los dioses controlan su vida, la de Mayorga está muy condicionada, a la manera de los personajes de la novela naturalista del siglo XIX, por una herencia genética convertida en sucedáneo de aquellos lejanos designios a los que resultaba imposible oponerse. Es el peso de una herencia que, dicho sea de paso, Unamuno convirtió en componente fundamental de su Fedra.

Pero ¿de qué herencia genética hablamos? En la conversación que en la escena 3 mantienen Fedra y Enone —este nombre procede de la versión de Jean Racine: en Eurípides el personaje es, simplemente, la nodriza - no queda claro cuál es esa historia que afecta a la madre de la primera tanto como para obsesionarla: "Recuerda a tu madre", le dice por dos veces Enone a Fedra (Mayorga, 2010: 49). Y esta, sin aclarar gran cosa al espectador, señala:

No dejo de pensar en ella. Cuando esto sucedió en mi corazón, pensé: "Otra vez. Ha ocurrido otra vez”. ¿Por qué en las de mi sangre al amor se une siempre la vergüenza? ¿Es nuestro destino sufrir deshonra en el amor? Recuerdo a mi madre, Enone, y cuánto la desprecié. Sé que no hay peso mayor que el crimen de una madre. No, mi hijo no vivirá con los ojos humillados. Recuerdo a mi madre, Enone, y prefiero la muerte antes que hacer lo que ella hizo (Mayorga, 2010: 49).

El conocedor del mito (no, ciertamente, el espectador medio) sabe a qué se refieren las oscuras palabras de la avergonzada Fedra. Su madre, Pasífae, incubó una pasión desenfrenada por un toro que Poseidón, dios de los mares, había entregado a Minos, esposo de aquella. El resultado fue el nacimiento de Minotauro, hombre y toro a la vez; aquel que fue derrotado por Teseo, el padre de Hipólito. A Fedra terminará ocurriéndole lo mismo que a su madre: por culpa de los crueles deseos divinos, la pasión amorosa arruinará su vida. Ese es el sentido de un recuerdo que al profano, sin la explicación, le parecerá un arcano poco menos que insondable.

Eurípides no es la única fuente utilizada por el dramaturgo español, pero la dependencia de este con respecto a aquel es clara, porque se escuchan en la Fedra de Mayorga ecos casi literales del Hipólito original. En un momento de la obra española, Enone afirma que "los mortales no deberíamos aspirar a una vida perfecta cuando ni siquiera somos capaces de ajustar el tejado que cubre nuestra casa" (Mayorga, 2010: 61), aseveración muy similar a esta contenida en el texto de Eurípides (1972: 23): "Los mortales no deben de querer su vida demasiado perfecta; pues ni el techo que cubre su morada son capaces de ajustarlo perfectamente". De la extensa diatriba de Hipólito contra las mujeres incluida en el texto del trágico griego extracto el siguiente fragmento:

¡Oh Zeus!, ¿por qué bajo los rayos del sol has hecho que existieran las mujeres, metal de falsa ley para los hombres? Si querías propagar la raza humana, debía esta no nacer de las mujeres, sino que los mortales, ofrendando en tus templos el oro, el hierro, el bronce, adquirieran la simiente de hijos, según su ofrenda cada uno; y vivieran en casas libres, sin mujeres (Eurípides, 1972: 29-30). 
Compárense las anteriores palabras del Hipólito griego con las siguientes de su homónimo de Mayorga:

Maldito amor y malditas mujeres, que esparcís por el mundo su veneno. ¿Por qué hay mujeres? Ojalá la raza humana pudiera extenderse sin vosotras. Ojalá los hombres pudiéramos comprar la simiente de los hijos y vivir en casas libres de mujeres. Vosotras solo traéis desgracias a las casas (Mayorga, 2010: 81-82).

La alusión al veneno, dicho sea de paso, recuerda una frase de la escena VI del acto III de la Fedra de Racine (2017: 61): "Un funesto veneno ha esparcido el amor por toda nuestra casa."

Vuelvo a Eurípides. Los reparos de Fedra y la réplica de la nodriza son prácticamente idénticos en uno y otro caso:

FEDRA.- ¡Me das horror! ¡No sellarás tu boca y dejarás de repetir cosas infames!

NODRIZA.- Infames, pero mejores para ti que las más nobles. Es mejor esta acción, si ha de salvarte, que tu buen nombre, por orgullo del cual vas a morir (Eurípides, 1972: 24).

FEDRA.- Me espanta oírte hablar así. Deja de decir palabras vergonzosas.

NoDRIZA.- Vergonzosas, pero buenas para ti. [...] Créeme, Fedra, es mejor ceder al deseo, por oscuro que parezca, que morir por un buen nombre (Mayorga, 2010: 63).

Y ya que hablamos de relaciones textuales, recordemos que Unamuno no puso la diatriba contra la mujer en boca de Hipólito, sino en la de su padre y, además, coherentemente con la condensación que caracteriza el texto del filósofo, el enfado del personaje se resuelve en una sola frase: “¡Fue la mujer, la mujer la que introdujo la culpa en el mundo!” (Unamuno, 1988: 218).

Analizaré a continuación, muy sucintamente, las características de los personajes fundamentales de la obra. Si la trama de Mayorga está humanizada con respecto a otras versiones previas, lo mismo sucede con los personajes que la ejecutan, quienes, en líneas generales, no se apartan del guion mítico conocido. A diferencia de versiones más radicales, como la de Domingo Miras (1995) o la de Lourdes Ortiz (2013), por no hablar de la experimental de Raúl Hernández Garrido (1999), la de Mayorga es respetuosa con el modelo tradicional. Por eso las conductas de los personajes de la Fedra de Mayorga no son muy distintas de las que definen a los ideados por Eurípides. Podría decirse, de hecho, que quien conozca el mito no se verá en absoluto sorprendido ante la versión de Mayorga... hasta llegar al desenlace.

Explicaciones y / o justificaciones sobre el comportamiento de Fedra ha habido muchas a lo largo de la historia. La conducta del personaje de Mayorga podría considerarse reprobable antes de que en la obra surja su deseo prohibido. Y ello porque ya antes había desplazado a la madre natural de Hipólito y más tarde se había dedicado a maltratar psicológicamente a este. Ahora pretende sustituir en la cama al padre por el hijo.

La pasión de Fedra hacia su hijastro ¿se desarrolla teniendo o no la certeza de que el ausente Teseo está muerto? Porque, como sucede en el original de Eurípides, la aparición de este no se produce hasta bien avanzada la obra. En Sófocles, Teseo se encontraba en los infiernos. En las versiones posteriores está guerreando fuera de Atenas, pero en unas ocasiones se le da por muerto y en otras no. 
El juicio moral que merece el hecho de que Fedra desee disfrutar de la compañía íntima del hijastro es, obviamente, distinto en función de que ella sea o no sabedora de la muerte de Teseo, porque el hecho de que no tenga la seguridad de que su marido ha muerto la convertiría en una mujer carente de escrúpulos. En cualquier caso, sepa, intuya o desconozca la muerte de su esposo, Fedra no es en la obra de Mayorga capaz de plantearse reflexiones morales, porque el deseo sexual se impone en ella por encima de consideraciones como la prudencia, el respeto y el decoro. Carece, pues, de sophrosyne, de autocontrol y moderación. El caso de la Fedra de Eurípides es muy distinto, porque la disculpa el hecho de que el poder de los dioses es absoluto: nada puede hacer ante él sino doblegarse. El personaje de Mayorga, sin embargo, es libre, puesto que no hay dioses a los que someterse. Por consiguiente, su conducta resulta moralmente reprobable, a no ser que aceptemos que el poder de la pasión sexual es tan grande que cualquier cosa puede o debe estar por debajo de ella.

En línea con la tradición del mito, la caracterización de Hipólito no ofrece aristas en el texto de Mayorga. Es un ser puro, enteramente ajeno a otra pasión que no sea la del disfrute de una naturaleza que simboliza la limpieza de su espíritu, rasgo distintivo del carácter del personaje:

Vivo como deseo vivir, y me es indiferente lo que los demás penséis de mí. Si os soy simpático o antipático, tanto me da. Nunca fingiré por complacer a nadie. Yo no engaño a nadie, porque a nadie envidio. El mundo está lleno de impostores que mienten con sus palabras y con sus hechos porque desearían ser otros que quienes son. Yo soy feliz en el bosque (Mayorga, 2010: 68).

Ante el problema planteado a su señora, el pensamiento de la nodriza experimenta un cambio, desde la inicial negación absoluta hasta el celestineo, que ya figuraba en otras versiones -incluido el Hipólito de Eurípides-. En la escena 3 había pretendido que su señora olvidara el mal pensamiento que representa su atracción por el hijastro:

No hablaremos de ello si tú juras no pensar más en ese hombre. No basta que renuncies con tu palabra si en tu cabeza te entregas a él. Los deseos absurdos hay que ahogarlos en el alma antes de que ahoguen el cuerpo. Ni en el pensamiento puedes aceptar ese deseo fatal. Mezclar el lecho del padre y el del hijo, incluso en la fantasía, es trastornar la naturaleza (Mayorga, 2010: 48).

En su siguiente aparición, sin embargo, Enone ha mudado de parecer: "El amor te ha elegido y nada podrás contra él. No busques razones para evitarlo, el amor no escuchará tus razones" (Mayorga, 2010: 63). Hasta ese momento, Fedra se ha mostrado dubitativa; dominada por la pasión, sí, pero aún reacia a internarse por la senda peligrosa: "No sigas hablando, Enone. Por mucho que adornes la infamia, no haré lo que no debo hacer" (Mayorga, 2010: 63-64). La nodriza incluso ha apelado, inútilmente, a la posibilidad de que de la sucesión de Teseo no se beneficie su hijo, sino Hipólito. Lo que parece impulsar la conducta de Enone es el deseo de que su señora no sea definitivamente vencida por el mal de amores.

Teseo aparece por primera vez en la escena 10. En la anterior se ha dicho de él que "parece que viniese del infierno" (Mayorga, 2010: 89). Efectivamente, es parte de la tradición mítica la estancia de Teseo en el Hades. Su viaje fuera de Atenas lo narra en la versión de Mayorga él mismo, de una manera extrañamente simbólica, como si se tratara de una pesadilla: "He estado en la tierra de los muertos", 
el "infierno". Afirma, además, haber estado en un banquete en el que se sintió acompañado por las sombras de aquellos hombres a quienes había matado (Mayorga, 2010: 92-93). Y es que, ciertamente, el mito recoge la historia de una invitación realizada por el dios Hades para un banquete, de resultas de la cual Teseo quedó encadenado hasta su liberación. Es otra muestra de la fidelidad de Mayorga a la tradición, aunque no, en este caso, al original de Eurípides, porque en él no aparece este relato de Teseo.

En la versión que aquí comento el rey, engañado por Fedra, es, como de costumbre en la tradición, culpable de la muerte de su hijo, puesto que, al creer la mentira de la mujer, lo envía al destierro. Lo interesante del personaje radica en el hecho de que, además de ser, como ocurre en todas las interpretaciones del mito, un elemento desencadenante del desastre, su culpabilidad queda reforzada por un detalle aparentemente nimio y, sin embargo, relevante, porque, con un movimiento en apariencia inocente — “A un gesto de Teseo, todos se apartan dejando solos a Fedra e Hipólito"; Mayorga, 2010: 119- facilita el encuentro final, a solas, de los dos protagonistas de la tragedia. Y es así como se produce un desenlace inesperado: Hipólito aún vive, agonizante, y Fedra lo remata antes de suicidarse, y antes de la última acotación, una de las pocas existentes en el texto: "El bosque arde" (Mayorga, 2010: 119).

Lo normal, de haberse ajustado a la tradición, hubiera sido la desaparición previa de Fedra. En el final de Mayorga está presente hasta el último segundo, trasladando entonces un mensaje que podría identificarse con una idea próxima al sentimiento de locura, en el fondo su verdadera enfermedad: "El mundo no quiso nuestro amor, pero nuestro amor es más grande que el mundo" (Mayorga, 2010: 119). A la locura, refiriéndose a Fedra, había aludido en la escena 8 Hipólito (Mayorga, 2010: 81), y de locura y demencia acababa de hablar, sobre el mismo personaje, Enone (Mayorga, 2010: 118). Es decir: Fedra está loca de amor, lo cual, desde el punto de vista de la verosimilitud, explica su crimen y su suicidio, prácticamente simultáneos ambos. Esa verosimilitud es una constante en la obra de Mayorga, excepto en dos momentos concretos: el posible descenso de Teseo a los infiernos y la muerte de Hipólito.

Al primero de estos elementos de la trama ya me he referido. Vayamos con el segundo, porque reflexionar sobre él permitirá plantear la cuestión de las relaciones entre texto teatral y representación escénica.

Comentar la pieza de Mayorga a partir de lo que fue su representación en Mérida y en otros escenarios españoles supone, en mi opinión, tergiversar el texto escrito. Las prologuistas de la edición, Mabel Brizuela y María Amelia Hernández, creen apreciar en Hipólito, "sobre todo en la última escena", "un sentimiento semejante al amor" (Brizuela y Hernández, 2010: 22). La segunda de estas autoras desarrolla una idea similar en otro trabajo al referirse "al amor por Fedra que se puede leer o entre leer en dos huellas del texto" (Hernández, 2008), huellas que no menciona, aunque es fácil deducir de cuáles se trata.

Resulta relevante, a efectos de interpretación de la obra, precisar que en la última y trágica escena del texto Hipólito no habla, porque está agonizando; únicamente interviene Fedra. El plural que utiliza 
esta — "Nada ni nadie podrá ya separarnos", "Mas ni el cielo ni los hombres pudieron impedir que nos amásemos": Mayorga, 2010: 119- más me parece una manifestación de demencia egocéntrica que expresión de unas supuestas relaciones consentidas que no se atisban en las escenas anteriores. La Fedra de Mayorga está loca — de amor-y, por tanto, es mucho más que probable que sus palabras respondan a un desiderátum y no a un análisis sosegado de la realidad, que es el que, en una circunstancia como esa, realizaría una persona en sus cabales.

¿Cuál es el problema que estoy sugiriendo? Cuando la obra se representó, bajo la dirección de José Carlos Plaza, este optó por dar a la escena final un sentido que debió de parecerle más trasgresor, más revolucionario, pero que no figura en el texto. Ya en sus declaraciones a la prensa antes del estreno parecía evidente — es algo muy habitual en el mundo de la dirección escénica- el deseo de exprimir el texto para sacarle un jugo ideológico: la Fedra que iba a contemplar el espectador tenía que ser interpretada en clave de reacción contra la derecha política. La afirmación del director de escena recogida por Rosana Torres en El País del 12 de julio de 2007 da una pista sobre el particular: "Es una obra de introspección y en tiempos retrógrados, como estos, mirar hacia el ser humano es todo un avance" (Torres, 2007).

En principio, una declaración de principios como esta poco nos dice sobre la intención de quien la formula, porque casi toda la gente de teatro dice o escribe cosas muy parecidas a esta antes de prácticamente cualquier representación. Pero si hacemos una pesquisa en los medios de comunicación que por esas fechas registraban declaraciones de Plaza, la pista quedará más limpia de guijarros. Sin comillas, leemos en El Confidencial de esa misma fecha que "Plaza indicó que Fedra representa la pasión por el amor por encima de los principios burgueses". "Tiempos retrógrados, como estos", "principios burgueses"... Nos vamos aproximando al foco de la interpretación.

...Que no es otra que la recogida en este último medio informativo, y esta vez sí, con comillas incluidas: "Un «canto de progresismo», agregó, en una sociedad donde la «labor de la derecha» lleva a «lo retrógrado y a volver al Franquismo»". Esta fue, textualmente, la información trasmitida por el redactor de la agencia EFE que cubría la rueda de prensa de Plaza, y por eso aparece reproducida, en los mismos términos, en al menos otro periódico, El Norte de Castilla, en ese mismo 12 de julio de 2007.

Ya tenemos más claro, me parece, por qué José Carlos Plaza alteró el significado del desenlace. Ese propósito de enfocar el texto de una determinada manera explica que quien no conociera lo escrito y tuviese como única referencia la representación viera lo que Mayorga no escribió. Conocer la representación, pero no el texto escrito (que, hay que recordarlo, se publicó más tarde, en 2010), permite comprender los comentarios sobre lo que pudo verse después de la primera representación emeritense, y que serán objeto de tratamiento en las páginas que siguen.

Así, en la reseña que Magda Ruggeri Marchetti (2007: 157) hizo de la representación en el teatro Bellas Artes de Madrid se podía leer lo siguiente sobre Hipólito:

Si al principio parece odiar a todas las mujeres, evoluciona en el curso de la obra porque Fedra conseguirá suscitar en él el amor, un amor que él no ha querido reconocer pero que poco a poco ha crecido 
en su corazón. El joven ha revelado claramente su sentimiento no denunciando el acoso amoroso de su madrastra y especialmente con su dulce mirada hacia ella en el final.

Esta misma opinión la sostiene Pilar Andreu Rovira (s. f.: 209): “el fet és que Fedra ha hagut de sofrir sigles d'espera perquè el seu amor fos feliçment correspot." Nos encontramos ante el eterno dilema entre texto y representación. Hace mucho tiempo que la crítica deslinda con nitidez la escritura teatral y la representación teatral: texto y espectáculo. No pretendo agotar las reflexiones sobre este tema, ni tampoco elaborar un repertorio de citas. Únicamente traeré a colación un par de ellas. Una de Edward A. Wright (1962: 32): "La obra o texto escrito es solo una parte de la producción teatral. [...] El texto escrito es solo eso hasta que se convierte en la pieza teatral al ser representada en el escenario por los actores y ante un público". Otra, más reciente, y si cabe más radical, la de Ricard Salvat (1983: 8):

\footnotetext{
Para toda persona de teatro, para todo teatrista, si usamos el término habitual en algunas repúblicas sudamericanas, el llamado "teatro para leer" es un grave atentado contra la especificidad del lenguaje teatral. El teatro en su calidad de texto solo sirve en la medida en que da pie a un espectáculo.
}

Esta falta de identificación entre texto y representación teatral es lo que puede permitir que, como principio general, sean legítimas dos interpretaciones de esta obra de Mayorga opuestas: la de quien se ajusta al texto y la de quien únicamente conoce la puesta en escena. Este último fue el caso de la totalidad de los cronistas, en un buen número de ciudades españolas, de la representación a la que me estoy refiriendo. La información apareció en todos los periódicos relevantes, nacionales, regionales y locales, tanto impresos como aparecidos en internet, pero solo los que he mencionado, que yo sepa, registran con precisión el sesgo ideológico que Plaza dio a su puesta en escena. Las reseñas, por lo demás, fueron habitualmente planas o elogiosas (se sale de este marco la menos complaciente de Pablo Bujalance [2010] en Málaga hoy).

Insistamos, pues, en lo que el texto no dice pero el director de escena quiso que sugiriera. Las palabras de Fedra en el texto publicado son las siguientes: "Hipólito ya no puede hablar, pero sí sus ojos. ¿Te preguntas por qué Hipólito no dijo la verdad? ¿Por qué me protegió, condenándose? Mira sus ojos y comprenderás. ¿No ves lo que te piden esos ojos? ¿Vas a ser cruel con tu hijo hasta el final?” (Mayorga, 2010: 118). Y Teseo, sin que pueda explicarse el porqué, se aleja en ese momento. Lo que se deduce del texto, creo, es que el agonizante Hipólito se encuentra ya instalado al margen de la realidad. Lo que se vio en la representación, en consecuencia, no está en el texto, y la mujer que ha pronunciado esas palabras es una demente enamorada, incapaz, por tanto, de reconocer la realidad objetiva.

A partir de lo que el texto dice, el director de escena puede sentirse libre de rebasar por su cuenta los límites de la escritura, puesto que el teatro está definido por unos límites mucho más flexibles que los que definen otros géneros. Entre otros motivos, porque la novela y la poesía se leen, mientras que el teatro se ve. Pero el texto es anterior a la representación y teóricamente, esta depende de aquel. ¿Para qué repensar aquí sobre el enfado de tantos espectadores forzados a ver en las representaciones apenas desvaídas sombras de lo que saben que son los textos pensados por los escritores? 
Las dos posturas extremas sobre la relación existente entre un texto teatral y su representación escénica dificultan una consideración razonable. Me resulta poco menos que imposible discrepar de la siguiente afirmación de Kurt Spang (1991: 24-25):

El drama es por naturaleza el texto junto con su representación; el texto dramático constituye una especie de partitura sui géneris que precisa de la adecuada "ejecución" para poder convertirse en auténtico drama. [...] De estos presupuestos se deriva lógicamente que si la lectura solitaria de una obra de teatro es posible y legítima, siempre será distinta de una representación, porque esta es la suma del texto y de lo que hacen de él tanto el director de teatro como cada actor y el conjunto de los demás especialistas que intervienen en la puesta en escena.

Entre los teóricos que quizá han pugnado con más insistencia por no caerse del alambre de la teoría está Jirí Veltrusky, cuyas lejanas palabras de 1942, reproducidas o revisadas en la edición en inglés fechada varias décadas después y publicada en español en 1990, solicitan el mantenimiento del equilibrio (Veltrusky, 1990: 15):

\footnotetext{
Algunos teóricos han llegado incluso a excluir el drama de la literatura y a declarar que se trata meramente del componente verbal del teatro. Esta concepción contradice, por supuesto, muchos hechos. A veces el drama se funde en la literatura lírica o narrativa, y a la larga surge de ellas nuevamente, como en la Edad Media. Muchas obras han sido escritas no para ser representadas teatralmente, sino simplemente para ser leídas.
}

Esto es, con otras palabras, lo mismo que decía el autor casi siete lustros después: "El drama, es decir, el texto escrito, ejerce una intensa presión sobre todos los componentes de la representación, es decir, del teatro; sin embargo, ninguno de ellos se somete a su presión absoluta e incondicionalmente" (Veltrusky, 1997: 53).

Cualquier espectador habitual es consciente del hecho de que ver en la representación algo no significa, ni muchísimo menos, que ese algo figure en el texto. Aquí, por ejemplo, el autor del texto no dice lo que el director de escena le hizo decir. El estudioso de la literatura habitualmente se basa en lo que el autor escribió, mientras que el estudioso del teatro prefiere complementar ese material con la representación. ¿Es legítimo que el director de escena interprete por su cuenta lo que acaso el autor no quiso que se viera de esa forma? Quizá el propio autor se sienta satisfecho, a posteriori, con la propuesta del director de escena. Pero tal vez no, aunque solo sea porque no fue la suya, aquella en la que pensó al escribir.

Cualquiera de las dos soluciones que estoy comentando a propósito de Fedra es teatralmente eficaz. El problema lo encuentro más en el plano de la recepción que en el del proceso de creación. Y ello porque quien viera la representación se quedaría con una idea del texto que no es real, sino, como mucho, posible. Si se quiere simplificar lo que deseo decir, podría afirmarse que habrá presenciado una Fedra de Mayorga tergiversada, dado que el desenlace condiciona, y mucho, cualquier interpretación.

Lo cual no obsta para que reconozca la dificultad de situar el texto como elemento dominante en el hecho teatral. Cada caso es, o puede ser, un mundo distinto, y de ahí que, aun admitiendo la validez 
de la siguiente consideración de M. ${ }^{a}$ del C. Bobes Naves (1997: 306), no la considere aplicable al caso de que me ocupo:

No está fijado nunca, porque es imposible hacerlo, un sentido único para el texto literario, y no está fijado, porque tampoco puede estarlo, un sentido único para los signos no lingüísticos, pero artísticos, que intervienen en la representación. No puede haber, por tanto, correspondencia unívoca entre dos realidades plurivalentes semánticamente. El sentido del texto —uno de sus sentidos-, dada su ambigüedad semántica y lo que suele alcanzarse, es una intersección de sentidos, más o menos amplia y coherente.

Sin embargo, si se lee el párrafo anterior a este que acabo de reproducir, podrá advertirse que la autora se refiere a los "signos acústicos y visuales". Es una puntualización muy necesaria para prevenir al lector de este trabajo sobre el alcance de mis consideraciones.

Hay en la versión de Mayorga un último punto que me sorprende, sobre todo teniendo presentes las fórmulas utilizadas por todos aquellos escritores que lo precedieron en la recreación del mito. Si no se quiere romper con este, hay que matar a Hipólito antes de que termine la pieza. En Mayorga, como en otras versiones, surge de las profundidades marinas un monstruo que provoca las heridas mortales del desdichado joven. Con esa aparición sobrenatural se rompe la constante de verosimilitud, principio rector de casi todo el argumento de su Fedra.

¿Hasta tal punto quiso Mayorga respetar el original de Eurípides que optó por mantener esta desviación antirrealista? Es el suyo un extraño, aunque coherente con la tradición, desenlace para una versión del siglo XXI. ¿Respeto reverencial al texto primigenio o efecto teatral, aunque sea narrado, para preparar la escena del crimen y el inmediato suicidio? No tengo la respuesta, entre otros motivos porque plantearnos esta cuestión supondría desarrollar el concepto de verosimilitud en el teatro contemporáneo, y no el de relaciones entre un texto teatral y su correspondiente puesta en escena, que era el tema de este trabajo.

\section{Bibliografía}

ANDREu RoviRA, P. (s. f.). Fedra, segles d'espera per un amor correspost. Extraído el 17 de marzo de 2019 desde https://www.core.ac.uk/download/pdf/39114597.pdf.

Bobes Naves, M. a del C. (1997). "Posibilidades de una semiología del teatro". En María del Carmen Bobes NAves (Comp.), Teoría del teatro. Madrid: Arco Libro. 295-322 (texto fechado en 1991).

Brizuela, M., y Hernández, M. ${ }^{a}$ A. (2010). Prólogo. En J. Mayorga, Fedra (pp. 9-33). Oviedo: KRK.

Bujalance, P. (2010, 23 de enero). Un caso para la tragedia postmoderna. Málaga hoy. Recuperado de https://www.malagahoy.es/ocio/caso-tragedia-postmoderna_0_335367222.html.

EFE (2007, 12 de julio). Una Fedra con solo texto, interpretación y música abrirá mañana la 53. ${ }^{a}$ edición del Festival de Mérida. El Confidencial y El Norte de Castilla. Recuperado de https://www.elconfidencial.com/cultura/2007-07-11/una-fedra-con-solo-texto-interpretacion-ymusica-abrira-manana-la-53a-edicion-del-festival.de-merida 371266. 
EURÍPIDES (1972). Hipólito. Madrid: Aguilar. Traducción, prólogo y notas por Francisco Rodríguez Adrados.

García ViÑó, M. (1975). Fedra. Madrid: Galería de Luis.

GARCíA ViÑó, M. (1983). El mito de Fedra (amor, libertad y culpa). Madrid: Fundación Universitaria Española.

HernándeZ, M. A A. (2008). Mayorga presenta "Fedra". Extraído el 12 de marzo de 2019 desde https://www.docplayer.es/83793885-Mayorga-presenta-fedra-lic-maria-amelia-hernandez.html. También en M. Brizuela (2011) (Ed.), Un espejo que despliega. El teatro de Juan Mayorga. Córdoba: Universidad Nacional de Córdoba.

HERnÁndez GARRIDO, R. (1999). Los restos: Fedra. Los restos: Agamenón vuelve a casa. Madrid: Fundación Autor.

MAYORGA, J. (2010). Fedra. Oviedo: KRK.

Miras, D. (1995). Fedra. En D. Miras, Teatro mitológico. Ciudad Real: Diputación Provincial de Ciudad Real.

Mougoyanni Hennessy, Ch. (2006). El mito disidente. Ulises y Fedra en el teatro español contemporáneo (1939-1999). Madrid: Mirabel.

ORTIZ, L. (2013). Fedra. Madrid: Ediciones Irreverentes.

PociñA, A., y LóPEZ, A. (2016). Reescrituras del tema de Fedra e Hipólito. En A. Pociña y A. LóPEZ (Eds.), Otras "Fedras": nuevos estudios sobre Fedra e Hipólito en el siglo XX (pp. 11-27). Granada: Universidad de Granada.

PociÑA, A., y LÓPEZ, A. (Coords.) (2008). Fedras de ayer y de hoy: teatro, poesía, narrativa y cine ante un mito clásico. Granada: Universidad de Granada.

RACINE, J. (2017). Fedra. Madrid: Rialp. Traducción, introducción y notas de Rafael Gómez Pérez.

RAGUÉ ARIAS, M. ${ }^{a}$ J. (1986). Los personajes femeninos de la tragedia griega en el teatro español del siglo XX. Barcelona: Universitat de Barcelona.

Ruggeri Marchetti, M. (2007). "Fedra”, de Juan Mayorga, en el Teatro Bellas Artes de Madrid. Extraído el 17 de marzo de 2019 desde https://www.raco.cat/index.php/assaigteatre/ article/viewFile/175585/249861, y https://studylib.es/doc/6229853/fedra-de-juan-mayorga-enel-teatro-bellas-artes-de-madrid. También en Assaig de Teatre. Revista de l'Associació d'Investigació i Experimentació Teatral, 60-61, 157-159.

Salvat, R. (1996). El teatro como texto, como espectáculo. (3. a ed.) Barcelona: Montesinos (1. a ed., 1983).

SÉneCA, L. A. (2016). Tragedias. II. Fedra. Edipo. Agamenón. Tiestes. Hércules en el Eta. Octavia. Barcelona: RBA. Introducciones, traducción y notas de Jesús Luque Moreno.

SPANG, K. (1991). Teoría del drama. Lectura y análisis de la obra teatral. Pamplona: Universidad de Navarra.

Torres, R. (2007, 12 de julio). Una 'Fedra' luminosa. Extraído el 17 de marzo de 2019 desde https://www.elpais.com/diario/2007/07/12/revistaverano/1184191204_850215.html 
Unamuno, M. de (1988). La esfinge. La venda. Fedra. Madrid: Castalia. Edición de José Paulino Ayuso.

Veltrusky, J. (1990). El drama como literatura. Buenos Aires: Galerna / IITCTL (1.a ed., 1942). Traducción de Milena Grass.

Veltrusky, J. (1997). “El texto dramático como uno de los componentes del teatro”. En María del Carmen Bobes NAVEs (Comp.), Teoría del teatro. Madrid: Arco / Libros. 31-55. Traducción de Lubomír Bartǒs (texto fechado en 1976).

Wright, E. A. (1962). Para comprender el teatro actual. Cine, Teatro y Televisión. México-Buenos Aires: Fondo de Cultura Económica (ed. en inglés, 1959). Traducción de Margo Glanz. 